\title{
Effects of fat distribution on lung function in young adults
}

Liqian Huang ${ }^{1}$, Ziliang Ye' ${ }^{2}$ Jingjing Lu², Cunqing Kong ${ }^{1}$, Qingqing Zhu², Binbin Huang ${ }^{2}$, Zerong Wang², Lin Xu', Qiongying Deng ${ }^{1}$, Jiangu Gong ${ }^{1}$ and Peng Liu ${ }^{1 *}$

\begin{abstract}
Aims: To study the associations between fat distribution and lung functions in healthy subjects of young adults and to explore potential gender difference in these correlations.

Methods: A total of 2101 adult participants were recruited. Height, weight, and vital capacity index (VCI) were measured and recorded according to the national physical fitness test standard. Body compositions, including body mass index (BMI), body fat percentage (BFP), waist-to-hip ratio (WHR), fat-free mass (FFM), trunk muscle mass (TMM), fat mass (FM), visceral fat area (VFA), visceral adipose tissue (VAT), and subcutaneous adipose tissue (SAT), were conducted using body composition analyzer. Data were analyzed by SPSS 20.0 software.

Results: We found that male participants showed significantly higher BMI, WHR, FFM, TMM, VFA, and VCl, but lower FM, BFP, and SAT in comparison with women. However, there was no significant difference in VAT between the male and female. Lung functions represented by VCI were negatively correlated with FM, VAT, SAT, and VFA for both men and women $(r<0 ; P<0.05)$. Among these negative correlations, $\mathrm{VCl}$ was more inversely correlated with VFA for men but with SAT for women, respectively. After dividing the whole populations by BMI, BFP, and WHR, further correlation analysis showed VCI was still more negatively correlated with VFA for all male subgroups $(r<0$; $P<0.05)$. On the contrary, $\mathrm{VCl}$ was more negatively correlated with SAT in BMl-underweight, BMI-normal, BFP-low fat, BFP-normal fat, WHR-normal, and WHR-obese subgroups $(r<0$; $P<0.05)$, while VFA and VAT was more inversely correlated with $\mathrm{VCl}$ in BMI- and BFP-overweight+obese subgroups $(r<0 ; P<0.05)$.
\end{abstract}

Conclusions: Fat accumulation is highly associated with the vital capacity index in young adults. In general, VCl was more negatively correlated with VFA for men but with SAT for women, respectively, in comparison with other tested indices.

Keywords: Visceral adipose tissue, Subcutaneous adipose tissue, Vital capacity index, Visceral fat area, College students

\section{Introduction}

Abdominal fat distribution has been associated with increased risk of different diseases, including cardiovascular disease, type 2 diabetes, and inflammatory bowel disease $[1,2]$. Increased abdominal fat distribution has been correlated with higher levels of triglyceride, total cholesterol, and low-density lipoprotein cholesterol, which contribute to subsequent high blood pressure and cardiovascular risk [3]. In a recent study, hip- and waist-

\footnotetext{
* Correspondence: drrliupeng@163.com

'Department of Anatomy, Guangxi Medical University, No. 22 Shuangyong

Road, Nanning 530021, Guangxi, China

Full list of author information is available at the end of the article
}

specific polygenic scores representing the levels of abdominal fat have been associated with higher blood pressure and higher risk of diabetes (waist-specific score: odds ratio (OR), 1.57; hip-specific score: OR, 2.54) and coronary disease (waist-specific score: OR, 1.60; hipspecific score: OR, 1.76) [4].

Breathing is an essential function for survival, and changes in pulmonary function can affect the quality of life and performance of daily activities. Previous studies have suggested that obesity is associated with impaired respiratory functions, including reduction in total lung capacity and forced vital capacity [5-7]. Obesity is also commonly found in association with chronic airway

(C) The Author(s). 2019 Open Access This article is distributed under the terms of the Creative Commons Attribution 4.0 International License (http://creativecommons.org/licenses/by/4.0/), which permits unrestricted use, distribution, and 
disease, like COPD and asthma [8]. Body mass index (BMI, calculated as weight in kilograms divided by height in meters squared) that is commonly used to define overweight or obesity has been negatively associated with lung functions evaluated by vital capacity, forced expiratory volume in $1 \mathrm{~s}$ (FEV1), and forced vital capacity (FVC) $[9,10]$. In addition, increased waist circumference (WC), waist-to-hip ratio (WHR), and body fat percentage (BFP) that are used to measure body fat distribution have been linked to impaired lung functions, which is suggestive of the essential roles of fat accumulation in lung functions [9-14].

The deposition of both subcutaneous adipose tissue (SAT) and visceral adipose tissue (VAT) determines the accumulation of abdominal fat. VAT and SAT are involved in metabolic activities and the production of proinflammatory adipocytokines [15]. In comparison with SAT, VAT is believed to be more important in the metabolic derangement, insulin resistance [16], dyslipidemia [17], and inflammation [18]. Since SAT and VAT differ in composition and function, it is relevant to establish the contribution of each to the association between abdominal obesity and lung function. Visceral fat, but not the SAT, WC, and BMI, has been inversely associated with FEV1 and FVC of men aged 50-70 years with the metabolic syndrome [19]. In addition, visceral adiposity is associated with the decrease in lung function in female asthma patients with a mean age of 55.39 years [20], whereas the observed associations between visceral adiposity and lung functions are limited to subjects with either metabolic syndrome or asthma, and it is unknown whether these associations are consistent in healthy subjects. Also, those correlations may be age dependent. In the current study, we recruited 2101 college students and take their advantages of being homogeneous to investigate the associations between fat distribution and lung functions. The BMI, BFP, WHR, fat-free mass (FFM), trunk muscle mass (TMM), fat mass (FM), visceral fat area (VFA), VAT, SAT, and vital capacity index (VCI, standard for lung function) were measured. We analyzed the association between lung function and VAT, SAT, and VFA as well as BMI, BFP, and WHR in young adults. The gender differences among these correlations were analyzed as well.

\section{Materials and methods}

\section{Subject}

A total of 2101 college students over 18 years of age were recruited from Guangxi Medical University after taking the approval of the Human Research Ethics Committee. Informed consent was taken from each participant. Participants with severe liver, respiratory, and cardiovascular diseases with previous medications of glucocorticoids and anti-tuberculosis drugs and with history of trauma and surgery in the past year were excluded. According to the inclusion criteria and exclusion criteria, 99 college students out of 2200 students were excluded from our study $(77 \mathrm{col}-$ lege students refused to participate in this study and 22 college students suffer from disease). The flow chart is shown in Fig. 1.

\section{Body composition}

Anthropometric measurements were performed for individual participant wearing light clothing without shoes. Height was measured to the nearest millimeter and weight to the nearest $0.1 \mathrm{~kg}$. Body composition indices were measured using bioelectrical impedance analysis (BIA) method by the body composition analyzer MC-180 (TANITA, Japan) including the BMI (expressed $\mathrm{kg} / \mathrm{m} 2$ ), FM, BFP, WHR, FFM, TMM, VFA, VAT, and SAT. Body compositions were measured by trained professional. In addition, we divided participants into different subgroups according to the built-in evaluation criteria of Ogilvy physical fitness management system and TANITA MC-180, as shown below [21]:

a. BMI-based criteria: underweight $(\mathrm{BMI}<18.5)$, normal weight $(18.5 \leq \mathrm{BMI}<24)$, overweight $(24 \leq$ BMI $<28)$, and obese $(\mathrm{BMI} \geq 28)$.

b. WHR-based criteria: for women, normal weight $(W H R<0.8)$ and obese (WHR $\geq 0.81)$; for men, normal weight $(\mathrm{WHR}<0.9)$ and obese $($ WHR $\geq$ 0.91).

c. BFP-based criteria: for women, low fat $(\leq 20 \%)$, normal fat (21-34\%), high fat (35-39\%), and obese $(\geq 40 \%)$; for men, low fat $(\leq 10 \%)$, normal fat $(11-$ $21 \%)$, high fat $(22-26 \%)$, and obese $(\geq 27 \%)$.

\section{Vital capacity test}

The vital capacity was measured using a spirometry meter (model number: WQS-8888, Wanqing Electronics, Shanghai, China) following the guidance of the national physical health test standard. In brief, prior to performing spirometry, the equipment was calibrated and each participant's identification was checked. Each individual was in a standing position with feet flat on floor and legs uncrossed. Tidal (normal) breaths were taken first, followed by a full inspiration along with head slightly backward. Each subject then exhaled steadily into the mouthpiece for as long as possible until there is no air left. Maximum value was recorded after three acceptable maneuver times. Detailed test methods referred to the interpretation of student physical health standard (trial scheme) published by People's Education Press, People's Republic of China. Since vital capacity is affected by body shape such as height and weight, we employed the vital capacity index with the consideration of the body mass, to represent the lung ventilation function [22]: the vital capacity index $=$ vital capacity/weight [23]. 


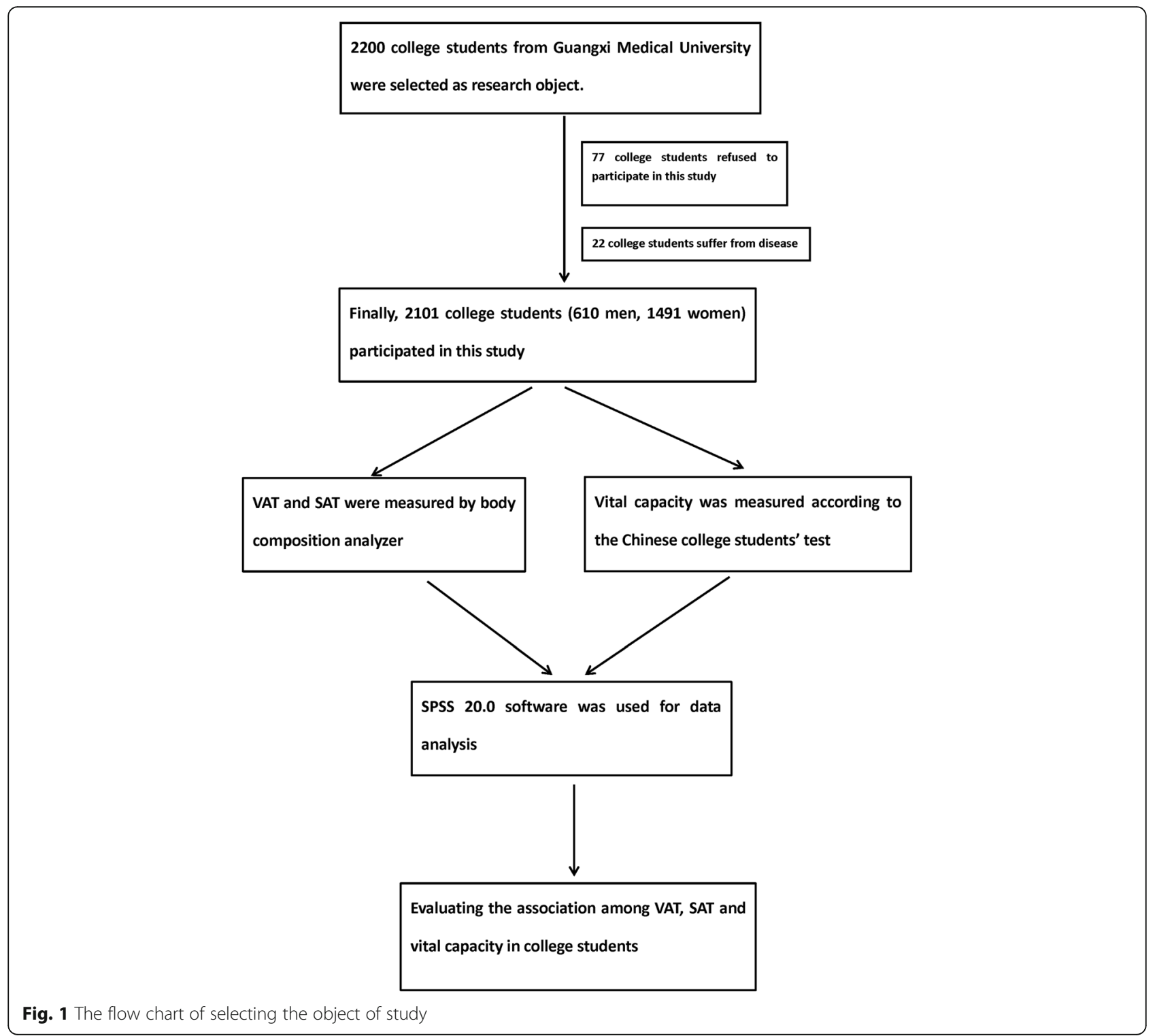

\section{Statistical analysis}

Results were presented as mean \pm SD. Statistical analysis was performed using the SPSS 20.0 software. Statistical significance was set at $P<0.05$. Statistical significance was assessed using analysis of variance (ANOVA). The confounding factors were adjusted by the covariance. Person's correlation analysis was used to explore the relationship between body composition and vital capacity index. Controlling FFM and TMM, partial correlation analysis was used to explore the relationship between adipose tissue and vital capacity index.

\section{Results}

The survey was completed by 2101 participants. The descriptive characteristics of body composition parameters and lung function test parameters between men and women are shown in Table 1. Male participants showed significantly higher BMI, WHR, FFM, TMM, VFA, and VCI, but lower FM, BFP, and SAT in comparison with women. However, there was no significant difference in VAT between the male and female.

Next, we explored the association between VCI and body composition indices. In Table 2, Pearson's correlation analysis showed, for men, negative correlations between VCI and FM, FFM, TMM, VAT, SAT, BMI, BFP, and WHR, respectively $(r<0, P<0.01)$. Women showed similar result as men, and FM, FFM, TMM, VAT, SAT, BMI, BFP, and WHR were negatively correlated with VCI $(r<0, P<0.01)$. As shown in Fig. 2 , the scatter plot analysis showed negative correlations between VAF, VAT, and SAT, and VCI in both men and women, respectively. 
Table 1 Characteristics of the participants

\begin{tabular}{lllll}
\hline Number & Total (2101) & Men (610) & Women (1491) & $P$ value \\
\hline Age (years) & $19.93 \pm 1.468$ & $20.02 \pm 1.494$ & $19.89 \pm 1.456$ & 0.051 \\
Height (cm) & $160.99 \pm 7.305$ & $169.01 \pm 5.881$ & $157.72 \pm 4.899$ & 0.000 \\
Weight $(\mathrm{kg})$ & $51.37 \pm 8.286$ & $58.79 \pm 8.866$ & $48.33 \pm 5.725$ & 0.000 \\
FFM & $40.84 \pm 7.475$ & $50.87 \pm 5.412$ & $36.74 \pm 2.957$ & 0.000 \\
TMM & $19.56 \pm 3.560$ & $24.14 \pm 2.704$ & $17.69 \pm 1.673$ & 0.000 \\
BMI & $19.74 \pm 2.312$ & $20.54 \pm 2.664$ & $19.41 \pm 2.063$ & 0.000 \\
FM (kg) & $10.55 \pm 4.319$ & $7.95 \pm 4.660$ & $11.61 \pm 3.676$ & 0.000 \\
BFP (\%) & $20.46 \pm 7.039$ & $12.87 \pm 5.539$ & $23.56 \pm 4.905$ & 0.000 \\
WHR & $0.80 \pm 0.048$ & $0.86 \pm 0.377$ & $0.78 \pm 0.248$ & 0.000 \\
VFA (cm $\left.{ }^{2}\right)$ & $18.69 \pm 17.602$ & $31.27 \pm 25.563$ & $13.54 \pm 8.843$ & 0.000 \\
VAT (kg) & $0.83 \pm 0.618$ & $0.87 \pm 0.858$ & $0.82 \pm 0.486$ & 0.167 \\
SAT (kg) & $9.70 \pm 3.798$ & $7.07 \pm 3.827$ & $10.78 \pm 3.215$ & 0.000 \\
VCl (mL/kg) & $55.89 \pm 11.498$ & $62.82 \pm 11.614$ & $53.06 \pm 10.175$ & 0.000 \\
\hline BMI body mass & &
\end{tabular}

$B M I$ body mass index, FFM fat-free mass, TMM trunk muscle mass, FM fat mass, BFP body fat percentage, WHR waist-to-hip ratio, VFA visceral fat area, VAT visceral adipose tissue, SAT subcutaneous adipose tissue, VC vital capacity, VCI vital capacity index

Since muscle mass and FFM have significant association with pulmonary function, we further performed partial correlation analysis after controlling FFM and TMM [24, 25]. As shown in Table 3, the partial correlation analysis showed that VCI was negatively correlated with FM, VFA, VAT, and SAT, respectively, after controlling for FFM and TMM for both men and women $(r<0$, $P<0.01)$. The strength of these negative correlations was $\mathrm{VFA}>\mathrm{SAT}>\mathrm{FM}>$ VAT $(r<0, P<0.01)$ for men, suggesting VFA was more negatively correlated with male VCI. While for women, the strength of these negative correlations was SAT $>$ FM $>$ VAT $>$ VFA $(r<0, P<0.01)$, which suggested SAT was more inversely correlated with female VCI. Taken together, these results suggested that $\mathrm{VCI}$ and fat distribution are negatively correlated for

Table 2 Pearson's correlation analysis between body composition indices and vital capacity index

\begin{tabular}{lllll}
\hline & Men & & & Women \\
\cline { 2 - 3 } & $r$ & $P$ value & $r$ & $P$ value \\
\hline FFM & -0.332 & $<0.01$ & -0.213 & $<0.01$ \\
TMM & -0.308 & $<0.01$ & -0.162 & $<0.01$ \\
FM & -0.409 & $<0.01$ & -0.350 & $<0.01$ \\
VFA & -0.423 & $<0.01$ & -0.250 & $<0.01$ \\
VAT & -0.394 & $<0.01$ & -0.323 & $<0.01$ \\
SAT & -0.411 & $<0.01$ & -0.351 & $<0.01$ \\
BMI & -0.450 & $<0.01$ & -0.352 & $<0.01$ \\
BFP & -0.382 & $<0.01$ & -0.331 & $<0.01$ \\
WHR & -0.373 & $<0.01$ & -0.337 & $<0.01$ \\
\hline
\end{tabular}

FFM fat-free mass, TMM trunk muscle mass, FM fat mass, VFA visceral fat area, VAT visceral adipose tissue, $S A T$ subcutaneous adipose tissue, $B M I$ body mass index, BFP body fat percentage, WHR waist-to-hip ratio both men and women. Compared to other indices, VCI was more negatively correlated with VFA for men but SAT for women, respectively.

To illustrate these observations, we further divided the men (Table 4) and women (Table 5) into BMI-base, BFP-based, and WHR-based subgroups, separately. Because of the limited case numbers for both BMI-obese group and BFP-obese group, we combined overweight group and obese group together for analysis. For men, negative correlations between VCI and FM, VAF, VAT, and SAT were significant in BMI-normal, BFP-normal fat, and WHR-normal subgroups $(r<0, P<0.01)$, but not for other subgroups. Based on the correlation strength (Table 4), VCI was more negatively correlated to VFA in each of these subgroups, in comparison with other indices of body fat distribution.

For women, as shown in Table 5, negative correlations between VCI and FM, VAF, VAT, and SAT were significant for the BMI-normal, BMI-overweight+obese, BFPnormal fat, WHR-normal, and WHR-obese subgroups $(r<0, P<0.05)$. For BMI-underweight group and BFPlow fat group, $\mathrm{VCI}$ had a significant negative correlation with FM, VAT, and SAT $(r<0, P<0.05)$, but not VAF. The correlation coefficient (Table 5 ) indicated a relative strong negative relation between VCI and SAT in BMIunderweight, BMI-normal, BFP-low fat, BFP-normal fat, and WHR-normal. On the contrary, VAF and VAT were more inversely correlated with VCI in BMI-overweight, BMI -overweight+obese, and WHR-obese subgroups.

\section{Discussion}

In the current study, we recruited 2101 college students to study the effects of abdominal fat distribution on lung function in young adults. We found that VCI was negatively correlated with FM, VAT, SAT, and VFA through partial correlation analysis after controlling muscle mass. Among these negative correlations, VCI was more inversely correlated with VFA for men but with SAT for women, respectively. Further correlation analysis for BMI-, BFP-, and WHR-subgroups suggested VCI was more negatively correlated to VFA in each of these male subgroups, in comparison with other indices of body fat distribution. However, for women, strong negative correlations between VCI and SAT were observed only in BMIunderweight, BMI- normal, BFP-low fat, and BFP-normal fat subgroups. On the contrary, for BMI- and BFPoverweight+obese subgroups, VCI was more negatively correlated with VAF or VAT. We concluded that fat distribution is highly associated with lung function in young adults, and in general, VCI was more negatively correlated with VFA for men but with SAT for women, respectively, in comparison with other tested indices.

In addition to cardiovascular disease, type 2 diabetes, and inflammatory bowel disease, abdominal fat 
A

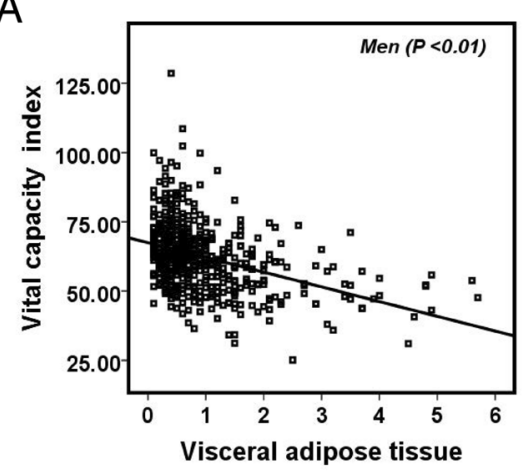

C

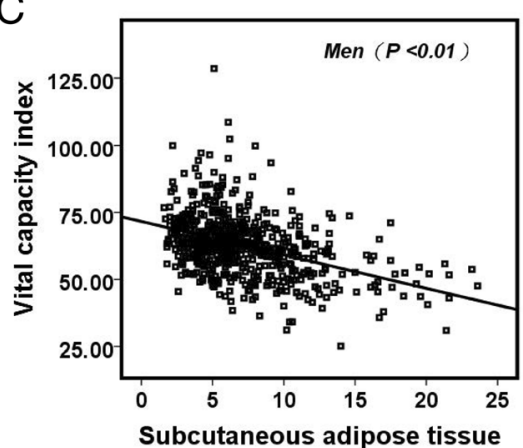

E

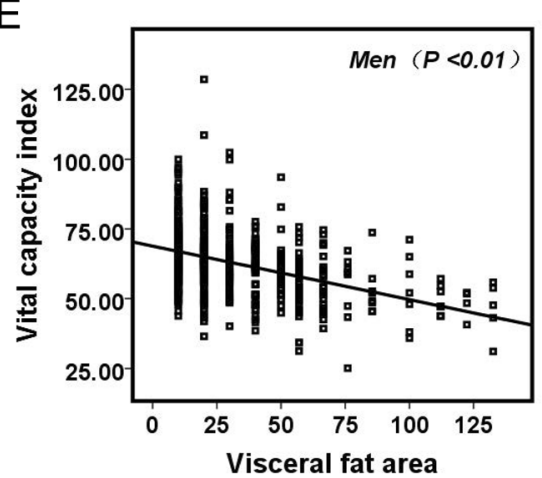

B

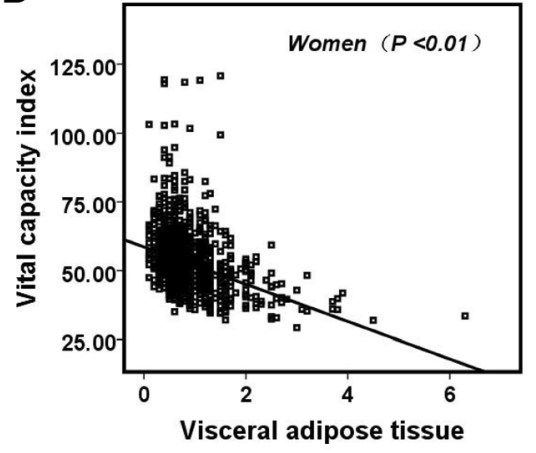

D

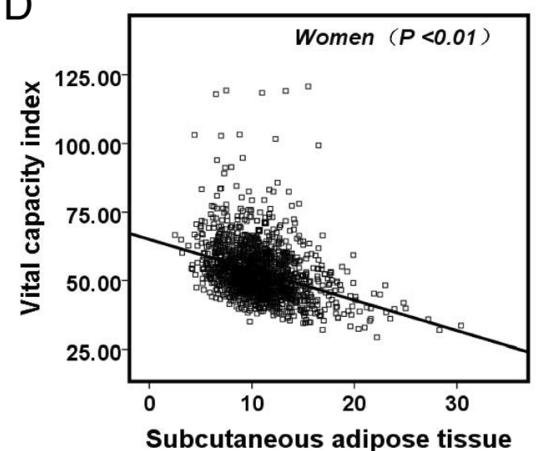

$\mathrm{F}$

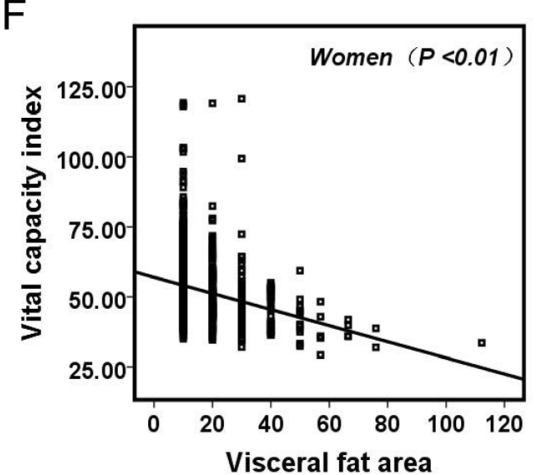

Fig. 2 Scatter plot of the correlation between visceral adipose tissue $(\mathbf{a}, \mathbf{b})$, visceral fat area $(\mathbf{e}, \mathbf{f})$, subcutaneous adipose tissue (c, $\mathbf{d})$, and vital capacity index (a-f). They all showed a negative correlation with the amount of vital capacity index, $P<0.01$ indicated that negative correlation was significant

Table 3 Partial correlation analysis between adipose tissue and vital capacity index

\begin{tabular}{|c|c|c|c|c|c|}
\hline \multicolumn{2}{|c|}{ Controlling variables } & \multicolumn{2}{|l|}{ Men } & \multicolumn{2}{|l|}{ Women } \\
\hline & & $r$ & $P$ value & $r$ & $P$ value \\
\hline \multirow[t]{4}{*}{ FFM and TMM } & FM & -0.290 & $<0.01$ & -0.281 & $<0.01$ \\
\hline & VFA & -0.294 & $<0.01$ & -0.182 & $<0.01$ \\
\hline & VAT & -0.274 & $<0.01$ & -0.256 & $<0.01$ \\
\hline & SAT & -0.292 & $<0.01$ & -0.282 & $<0.01$ \\
\hline
\end{tabular}

FM fat mass, VFA visceral fat area, VAT visceral adipose tissue, SAT subcutaneous adipose tissue distribution has been associated with impaired lung functions. Similar to other diseases [26, 27], different abdominal fat compartments and distributions may be differently associated with lung functions. However, only a few studies have assessed the independent associations of VAT and SAT with lung functions. Visceral fat, but not the SAT, WC, and BMI, has been inversely associated with impaired lung function of men aged 50-70 years with the metabolic syndrome [19]. In addition, visceral adiposity is associated with the decrease in lung function in female asthma patients with a mean age of 55.39 years [20]. These observations were obtained from the participants with the ages over 50 years and subjected to limitations of health conditions (metabolic syndrome or asthma). It is unclear 
Table 4 Partial correlation analysis between adipose tissue and vital capacity index in BMI-, BFP-, and WHR- based male subgroups

\begin{tabular}{|c|c|c|c|c|c|c|c|c|c|c|c|c|c|}
\hline & & \multicolumn{5}{|l|}{ BMI } & \multicolumn{5}{|l|}{ BFP } & \multicolumn{2}{|l|}{ WHR } \\
\hline & & Underweight & Normal & Overweight & Obese & $\begin{array}{l}\text { Overweight + } \\
\text { obese }\end{array}$ & $\begin{array}{l}\text { Low } \\
\text { fat }\end{array}$ & $\begin{array}{l}\text { Normal } \\
\text { fat }\end{array}$ & $\begin{array}{l}\text { High } \\
\text { fat }\end{array}$ & Obese & $\begin{array}{l}\text { Overweight + } \\
\text { obese }\end{array}$ & Normal & Obese \\
\hline $\begin{array}{l}\text { Controlling } \\
\text { variables }\end{array}$ & $n=$ & 136 & 408 & 52 & 14 & 66 & 260 & 306 & 30 & 14 & 44 & 527 & 83 \\
\hline \multirow{4}{*}{$\begin{array}{l}\text { FFM } \\
\text { and } \\
\text { TMM }\end{array}$} & FM & -0.136 & $\overline{-} .231^{* *}$ & -0.068 & 0.004 & -0.198 & $\overline{0} .053$ & $-\overline{0.187^{* *}}$ & $\overline{-} .094$ & $\overline{0}-329$ & -0.108 & $-\overline{0.203 * *}$ & $-\overline{0.175}$ \\
\hline & VAF & $<-0.001$ & $-\overline{0.237^{* *}}$ & -0.082 & $-\overline{0.174}$ & -0.233 & $-\overline{0}$ & $-\overline{0.193 * *}$ & $\overline{0}-012$ & $\overline{0.548}$ & -0.120 & $-\overline{0.200 * *}$ & $\overline{0} .192$ \\
\hline & VAT & -0.146 & $-\overline{0.235^{* *}}$ & -0.070 & 0.019 & -0.199 & $\overline{0}-048$ & $-\overline{0.179^{* *}}$ & $-\overline{0}$ & $\overline{-} .291$ & -0.106 & $-\overline{0.198^{* *}}$ & $\overline{0.156}$ \\
\hline & SAT & -0.136 & $-\overline{0.231^{* *}}$ & -0.067 & $\begin{array}{l}- \\
0.011\end{array}$ & -0.199 & $-\overline{0}$ & $\begin{array}{l}- \\
0.191^{* *}\end{array}$ & $-\overline{0}-078$ & $-\overline{0.355}$ & -0.110 & $-\overline{0.204^{* *}}$ & $\begin{array}{l}- \\
0.180\end{array}$ \\
\hline
\end{tabular}

FM fat mass, VFA visceral fat area, VAT visceral adipose tissue, SAT subcutaneous adipose tissue, BMI body mass index, BFP body fat percentage, WHR waist-to-hip ratio.

${ }^{* *} P<0.01$, with statistical significance

whether these associations are universal and applicable to healthy people. To address this question, we recruited college students in this study and take their advantages to investigate the association between fat accumulation and lung function. College student subjects are believed to be developmentally mature both physically and psychologically. In addition, they tend to be homogeneous on dimensions such as age, education, dwelling, and food source, as well as exercise behavior. Therefore, college student subjects might enhance research validity and minimize the possibility of undue influence because of their apparent homogeneity, especially for the research purpose targeting on young adults.

Dual energy X-ray absorptiometry (DXA) and bioelectrical impedance analysis are two common methods to determine body composition. DXA method is featured with high accuracy and has been recognized as a gold standard technique to measure human body composition [28, 29]. DXA can be used to determine either whole or regional body composition. However, this standard method is hardly feasible in routine clinical practice, especially in our current study with over 2000 participants. In addition, the radiation exposure from DXA may cause potential participants' psychological concerns and subsequently unwillingness to be involved in this project, though the method is safe. Therefore, in this study, we chose BIA method instead which has been considered inexpensive and rapid [30]. Some studies have shown good concordance between the two methods while others have not [31-39]. These conflicting results may probably be due to the differences in used equations, population size, age, ethnicity, gender, and body weights in the sample studied. A recent study that directly compares the measurement of FM and FFM by DXA and BIA methods in a large cohort of patients suggested that BIA and DXA methods are interchangeable at a population level and FM obtained by BIA and DXA were strongly correlated [31]. In particular, BMI between 16 and 18.5, body composition values measured by DXA and BIA were very closed. However, BIA method tends to overestimate or underestimate FM and FFM values beyond the above BMI range.

Table 5 Partial correlation analysis between adipose tissue and vital capacity index in BML-, BFP-, and WHR-based female subgroup

\begin{tabular}{|c|c|c|c|c|c|c|c|c|c|c|c|c|c|}
\hline & & \multicolumn{5}{|l|}{$\mathrm{BMl}$} & \multicolumn{5}{|l|}{ BFP } & \multicolumn{2}{|l|}{ WHR } \\
\hline & & Underweight & Normal & Overweight & Obese & $\begin{array}{l}\text { Overweight + } \\
\text { obese }\end{array}$ & $\begin{array}{l}\text { Low } \\
\text { fat }\end{array}$ & $\begin{array}{l}\text { Normal } \\
\text { fat }\end{array}$ & $\begin{array}{l}\text { High } \\
\text { fat }\end{array}$ & Obese & $\begin{array}{l}\text { Overweight + } \\
\text { obese }\end{array}$ & Normal & Obese \\
\hline $\begin{array}{l}\text { Controlling } \\
\text { variables }\end{array}$ & $n=$ & 472 & 977 & 35 & 7 & 42 & 424 & 1041 & 21 & 5 & 26 & 527 & 83 \\
\hline \multirow{4}{*}{$\begin{array}{l}\text { FFM } \\
\text { and } \\
\text { TMM }\end{array}$} & FM & $-0.195^{* *}$ & $-\overline{0.165^{* *}}$ & $-0.397^{*}$ & $-\overline{0.816}$ & $-0.421^{* *}$ & $-\overline{0.163^{* *}}$ & $\begin{array}{l}- \\
0.147^{* *}\end{array}$ & $\begin{array}{l}- \\
0.164\end{array}$ & $-\overline{0.607}$ & -0.214 & $-\overline{0.251^{* *}}$ & $-\overline{0.275^{* *}}$ \\
\hline & VAF & -0.028 & $-\overline{0.108^{* *}}$ & $-0.405^{*}$ & $\begin{array}{l}- \\
0.873\end{array}$ & $-0.428^{* *}$ & $\begin{array}{l}<- \\
0.001\end{array}$ & $-\overline{0.108^{* *}}$ & $\overline{0} .006$ & $-\overline{0.668}$ & -0.241 & $-\overline{0.094^{* *}}$ & $-\overline{0.257^{* *}}$ \\
\hline & VAT & $-0.170^{*}$ & $\overline{0.160 * *}$ & $-0.407^{*}$ & $\overline{0}-841$ & $-0.413^{* *}$ & $\overline{0.137^{* *}}$ & $\overline{-}-145^{* *}$ & 0.006 & $\begin{array}{l}- \\
0.574\end{array}$ & -0.245 & $\overline{0} .233^{* *}$ & $-\overline{0.280 * *}$ \\
\hline & SAT & $-0.196^{* *}$ & $-\overline{0.165^{* *}}$ & $-0.391^{*}$ & $-\overline{0.810}$ & $-0.421^{* *}$ & $-\overline{0.164^{* *}}$ & $\begin{array}{l}- \\
0.145^{* *}\end{array}$ & $\begin{array}{l}- \\
0.172\end{array}$ & $\begin{array}{l}- \\
0.616\end{array}$ & -0.204 & $-\overline{0.251^{* *}}$ & $-\overline{0.272^{* *}}$ \\
\hline
\end{tabular}

FM fat mass, VFA visceral fat area, VAT visceral adipose tissue, SAT subcutaneous adipose tissue, BMI body mass index, BFP body fat percentage, WHR waist-to-hip ratio

${ }^{*} P<0.05 ;{ }^{* *} P<0.01$, all with statistical significance 
Sex differences in fat distribution are well documented. Women are generally characterized by having more SAT, whereas men are more prone to high amounts of VAT [40-42], which is consistent with our finding although the VAT difference between men and women was not statistically significant. Of note, we also showed men had higher VFA than women. Gender is considered as an essential factor regulating the body composition, in particular the obesity, mostly upon genetic and epigenetic regulation [43]. Other biological differences between male and female also contribute to the different composition [44], including hormone expression and lifestyle. For example, estrogen could increase the decomposition of SAT but decrease VAT [45].

Jianhui et al. have found that the effects of different fat distribution on thoracic activity varied; central obesity tended to reduce diaphragm and chest activity significantly, while peripheral obesity had relatively slight effects on respiratory movement [46]. Since the fat distribution varies in men and women, it is reasonable that gender difference in fat distribution contributes differently to lung functions for men and women, in addition to the gender difference in lung morphology (lung size, airway diameter, and diffusion surface) and hormones [47-50]. In this study, VCI was negatively correlated with FM, VFA, VAT, and SAT, respectively, for both men and women. However, women's VCI was more negatively correlated with SAT, while male VCI was more inversely correlated with VFA, suggesting a gender difference of effects of fat distribution on lung functions, confirming our hypothesis. Such observation is probably due to the fact that compared with subcutaneous fat, the accumulation is more visceral for men [51], and the increase of visceral fat is faster, resulting in excessive accumulation of fat in the internal organs of the abdominal cavity and affecting lung ventilation function for male [52]. Therefore, visceral fat had a predominant impact on lung function than subcutaneous fat for young men. For women, a previous study by Park et al. showed that VAT rather than SAT is more important for pulmonary function in female with an average age of 53.4 years [53]. The difference may come from different employed indicators for lung function, VCI in our study vs FVC and FEV1 in the previous report. Another possibility is the age difference. Considering the fact that postmenopausal women tend to distribute fat in their viscera [54], it is plausible that the age difference contributed to the contradiction with the previous report.

To better understand these observed negative correlations, we performed further analysis by dividing participants into different subgroups based on the BMI, BFP, and WHR criteria. For men, VCI was more negatively correlated to VFA regardless of subgroups, in comparison with other indices of body fat distribution, suggesting VCI-VFA negative correlation is universal for the whole population. This is probably due to the fact that visceral fat deposition is predominant in young men regardless of obesity classification as discussed above [51]. On the contrary, female VCI was more negatively correlated with SAT in BMIunderweight, BMI-normal, BFP-low fat, BFP-normal fat, and WHR-normal subgroups, which is consistent with the finding as a whole female population. VFA and VAT were more inversely correlated with $\mathrm{VCI}$ in BMI-overweight, BMI-overweight+obese, and WHR-obese subgroups. Taken together, for women, the fat distribution indices of different subgroups have different effects on the lung functions. It is plausible that female's fat is mainly deposited under the skin but slowly in viscera before the body turning into overweighted or obese, which contributes to a negative correlation between SAT and VCI. However, during the development of obesity, fat tends to accumulate in visceral region since the amount of subcutaneous fat has plateaued. A previous study showed that obese women with high visceral fat have worse lung function compared to those with high subcutaneous fat under the same fat content [55]. Further studies or animal models are needed to illustrate the potential mechanism.

In addition to VAT, VFA, and SAT, we also showed that the BMI, FM, BFP, and WHR were negatively correlated with the vital capacity index. The increase of BMI, body fat rate, and WHR has been related to the development of obesity, whose increase is indicative of excessive fat accumulation in the abdominal cavity and on the chest wall. These changes will impair pulmonary function by affecting vital capacity and breathing regulation, as well as increasing the work of breathing, reducing lung volumes, rendering respiratory muscles dysfunctional, and impairing gas exchange [56-58]. In the present study, we also noticed gender differences in BMI, BFP, and WHR and the vital capacity index. Women's FM and BFP were higher than men, while men's BMI, WHR, and vital capacity index were higher than women.

The present study had several limitations. Firstly, lung function was only evaluated by vital capacity index due to a large sample size. FVC, FEV1, and FEV1/FVC are considered for later studies to establish the relationship between fat accumulation with other lung function indices. Secondly, because this study is cross-sectional, our study lacks the analysis about the causality underlying the relationship between fat accumulation and impaired lung function. Future experiment is expected to explain the effects of SAT and VAT on lung functions.

\section{Conclusion}

Taken together, we conclude that lung function is highly associated with abdominal fat distribution in young 
adults. Female and male VCIs are more negatively correlated with SAT and VFA separately.

\section{Acknowledgements}

We thank all the participants who volunteered to take part in this study and all the researchers of the research team.

All authors approve the manuscript for publication and declare that the work described was an original research that has not been published previously, in whole or in part. All the authors listed have approved the manuscript that is enclosed.

\section{Authors' contributions}

$\mathrm{LH}$ and CK wrote the first draft of the manuscript, helped interpret the results, and critically revised the manuscript. $Z Y$ and $J L$ supervised the data processing and helped interpret the statistical results. QZ, BH, ZW, and JG helped collect the data and interpret the results. LX, QD, and PL helped develop the questionnaire and interpret the results and critically revised the manuscript. All authors read and approved the final manuscript.

\section{Funding}

This study was supported by Guangxi colleges and Universities Key Laboratory of Human Development and Disease Research (NO: 0102402214009C), Guangxi Medical University innovation and entrepreneurship training program (NO: 2018009、2018112). Effects of physical activity on body composition and bone mineral density of Guangxi multi-ethnic college students (02601215001C).

\section{Availability of data and materials}

The datasets used during the current study are available from the corresponding authors on reasonable request.

\section{Ethics approval and consent to participate}

Participants of this study signed an informed consent form, and the study was approved by the Medical Ethics Committee of Guangxi Medical University.

\section{Consent for publication}

All participants have written consent for publication.

\section{Competing interests}

The authors declare that they have no competing interests.

\section{Author details}

'Department of Anatomy, Guangxi Medical University, No. 22 Shuangyong Road, Nanning 530021, Guangxi, China. ${ }^{2}$ Guangxi Medical University, Nanning 530021, Guangxi, China.

Received: 12 November 2018 Accepted: 23 May 2019 Published online: 24 June 2019

\section{References}

1. Hinnouho GM, Czernichow S, Dugravot A, et al. Metabolically healthy obesity and the risk of cardiovascular disease and type 2 diabetes: the Whitehall II cohort study. Eur Heart J. 2015;36(9):551-9.

2. Barroso T, Conway F, Emel S, et al. Patients with inflammatory bowel disease have higher abdominal adiposity and less skeletal mass than healthy controls. Ann Gastroenterol. 2018:31(5):566-71.

3. Scheuer SH, Faerch K, Philipsen A, et al. Abdominal fat distribution and cardiovascular risk in men and women with different levels of glucose tolerance. J Clin Endocrinol Metab. 2015;100(9):3340-7.

4. Lotta LA, Wittemans LBL, Zuber V, et al. Association of genetic variants related to gluteofemoral vs abdominal fat distribution with type 2 diabetes, coronary disease, and cardiovascular risk factors. JAMA. 2018;320:2553-63.

5. Littleton SW. Impact of obesity on respiratory function. Respirology. 2012; 17(1):43-9.

6. Wei YF, Wu HD, YungChieh Yen PD, et al. The impact of metabolic parameters on the change of pulmonary function in obese patients. Surg Obes Relat Dis. 2014;10(1):23-8

7. Melo LC, da Silva MAM, Calles AC d N. Obesity and lung function: a systematic review. Einstein. 2014;12(1):120-5.

8. Poulain M, Doucet M, Major GC, et al. The effect of obesity on chronic respiratory diseases: pathophysiology and therapeutic strategies. CMAJ. 2006;174(9):1293.
9. Wannamethee SG, Shaper AG, Whincup PH. Body fat distribution, body composition, and respiratory function in elderly men. Am J Clin Nutr. 2005; 82:996-1003.

10. Lessard $\mathrm{A}$, Alméras $\mathrm{N}$, Turcotte $\mathrm{H}$, et al. Adiposity and pulmonary function: relationship with body fat distribution and systemic inflammation. Clin Invest Med. 2011;34(2):64-70.

11. Chen $Y$, Rennie $D$, Cormier $Y F$, et al. Waist circumference is associated with pulmonary function in normal-weight, overweight, and obese subjects. Am J Clin Nutr. 2007:85:35-9.

12. Wehrmeister FC, Menezes AM, Muniz LC, et al. Waist circumference and pulmonary function: a systematic review and meta-analysis. Syst Rev. 2012;1(1):55.

13. Cotes JE, Chinn DJ, Reed JW. Body mass, fat percentage, and fat free mass as reference variables for lung function: effects on terms for age and sex. Thorax. 2001;56:839-44.

14. Koziel S, Ulijaszek SJ, Szklarska A, Bielicki T. The effects of fatness and fat distribution on respiratory functions. Ann Hum Biol. 2007;34(1):123-31.

15. Samaras K, Botelho NK, Chisholm DJ, et al. Subcutaneous and visceral adipose tissue gene expression of serum adipokines that predict type 2 diabetes. Obesity. 2010;18(5):884.

16. Preis SR, Massaro JM, Robins SJ, et al. Abdominal subcutaneous and visceral adipose tissue and insulin resistance in the Framingham Heart Study. Obesity. 2010;18(11):2191.

17. Oka R, Miura K, Sakurai M, et al. Impacts of visceral adipose tissue and subcutaneous adipose tissue on metabolic risk factors in middle-aged Japanese. Obesity. 2010;18(1):153.

18. Pou KM, Massaro JM, Hoffmann U, et al. Visceral and subcutaneous adipose tissue volumes are cross-sectionally related to markers of inflammation and oxidative stress: the Framingham Heart Study. Circulation. 2007;116(11):1234-41.

19. Thijs W, Dehnavi RA, Hiemstra PS, et al. Association of lung function measurements and visceral fat in men with metabolic syndrome. Respir Med. 2014;108(2):351-7.

20. Capelo A V , Da Fonseca V M , Peixoto M V M , et al. Visceral adiposity is associated with cytokines and decrease in lung function in women with persistent asthma. Rev Port Pneumol. 2016;22(5):255-261.

21. Zhou Xuan, Yu Hongrong, Li Yan, et al. Differences in body composition and age variation of adult women of ethnic minorities in Guangxi. J Anthropol. 2017;36(02):260-267.

22. Liu Xiaohui, Zhang Jing. Survey on growth and physical quality among grade three junior high school students in Shenbei new districts, Shenyang City 2005, 2014. Prev Med Forum. 2015(12):903-906.

23. Wang $Z$, Sun $J X$, Tao Y L, et al. Rationality of vital capacity index evaluation system - C Correlation analysis based on between vital capacity and morphological index. J Chengdu Sport Univ. 2013:39(7):86-90.

24. Liqian $H$, Qiaoli L, Binbin $H$, et al. The correlation between physical fitness test scores and body muscle parameters of male college students in Guangxi. Chinese J School Health. 2018;39(02):248-51.

25. Park JE, Chung JH, Shin KC, et al. The effect of body composition on pulmonary function. Tuberc Respir Dis. 2012;72(5):433.

26. Britton KA, Massaro JM, Murabito JM, et al. Body fat distribution, incident cardiovascular disease, cancer, and all-cause mortality. J Am Coll Cardiol. 2013;62(10):921-5

27. Neeland IJ, Ayers CR, Rohatgi AK, et al. Associations of visceral and abdominal subcutaneous adipose tissue with markers of cardiac and metabolic risk in obese adults. Obesity. 2013;21:E439-47.

28. Micklesfield LK, Evans J, Norris SA, et al. Dual-energy X-ray absorptiometry and anthropometric estimates of visceral fat in Black and White South African Women. Obesity. 2012;18(3):619-24.

29. Albanese CV, Diessel E, Genant HK. Clinical applications of body composition measurements using DXA. J Clin Densitom. 2003;6(2):75-85.

30. Gupta D, Lammersfeld CA, Burrows JL, et al. Bioelectrical impedance phase angle in clinical practice: implications for prognosis in advanced colorectal cancer. Am J Clin Nutr. 2005;80(6):1634-8.

31. Najate A, Guillaume C, Julie D, et al. Comparison of body composition assessment by DXA and BIA according to the body mass index: a retrospective study on 3655 measures. PLoS One. 2018;13(7):e0200465.

32. Neovius $M$, Hemmingsson E, Freyschuss $B$, et al. Bioelectrical impedance underestimates total and truncal fatness in abdominally obese women* Obesity. 2006;14(10):1731-8.

33. Hew-Butler T, Holexa B, Fogard K, et al. Comparison of body composition techniques before and after a $161-\mathrm{km}$ ultramarathon using DXA, BIS and BIA. Int J Sports Med. 2014;36(02):169-74. 
34. Pateyjohns IR, Brinkworth GD, Buckley JD, et al. Comparison of three bioelectrical impedance methods with DXA in overweight and obese men. Obesity. 2012;14(11):2064-70.

35. Stewart SP, Bramley PN, Heighton R, et al. Estimation of body composition from bioelectrical impedance of body segments: comparison with dualenergy X-ray absorptiometry. Br J Nutr. 1993;69(03):645.

36. Mattar L, Godart N, Melchior JC, et al. Underweight patients with anorexia nervosa: comparison of bioelectrical impedance analysis using five equations to dual X-ray absorptiometry. Clin Nutr. 2011;30(6):746-52.

37. Leahy $S, O^{\prime}$ Neill $C$, Sohun $R$, et al. A comparison of dual energy X-ray absorptiometry and bioelectrical impedance analysis to measure total and segmental body composition in healthy young adults. Eur J Appl Physiol. 2012;112(2):589-95.

38. Thomson R, Brinkworth GD, Buckley JD, et al. Good agreement between bioelectrical impedance and dual-energy $\mathrm{X}$-ray absorptiometry for estimating changes in body composition during weight loss in overweight young women. Clin Nutr. 2007;26(6):771-7.

39. Gába A, Kapu O, Cuberek $R$, et al. Comparison of multi- and singlefrequency bioelectrical impedance analysis with dual-energy $X$-ray absorptiometry for assessment of body composition in post-menopausal women: effects of body mass index and accelerometer-determined physical activity. J Hum Nutr Diet. 2015;28(4):390-400.

40. Geer EB, Shen W. Gender differences in insulin resistance, body composition, and energy balance. Gender Med. 2009;6:60-75.

41. Jinrong $Y$, Lei $L$, Jihong $S$, et al. Analysis of human body composition and its correlation with obesity in 555 college students. Chinese School Physicians. 2016;30(11):815-6.

42. Tchernof A, Despres JP. Pathophysiology of human visceral obesity: an update. Physiol Rev. 2013;93(1):359-404.

43. Herrera BM, Keildson S, Lindgren CM. Genetics and epigenetics of obesity. Maturitas. 2011;69(1):41-9.

44. Horlick M, Arpadi SM, Bethel J, et al. Bioelectrical impedance analysis models for prediction of total body water and fat-free mass in healthy and HIV-infected children and adolescents. Am J Clin Nutr. 2002;76(5):991-9.

45. Zhao Wenyan, Dong Yao, Qiu Shun. The expression of estrogen receptor in adipocytes and its correlation with fat distribution in human body. Chin J Aesthetic Med. 2005;14(05):534-536.

46. Jianhui C, Li X, Yulong Z, et al. The correlation between obesity of different types and pulmonary function, trachea and systemic inflammation and disease control in asthmatic patients. Chinese J Clin Nutr. 2014;22(4):209-12.

47. Harms CA. Does gender affect pulmonary function and exercise capacity? Respir Physiol Neurobiol. 2006;151(2):124-31.

48. Li Xueting, Liu Hui, Jiang Qi, et al. Characteristic analysis of growth and development of body composition in 6 15 years old children in Haidian district of Beijing. Chin J Chem Child Health Care. 2017;25(10):998-1001.

49. Janzen B, Karunanayake C, Rennie D, et al. Gender differences in the association of individual and contextual exposures with lung function in a rural Canadian population. Lung. 2016;195(1):1-10.

50. Teng $K$ Q, Zheng D S, Feng $Y$ M. A study on influencing factors of lung function before and after ambient air pollution among primary students in Miyun District of Beijing in 2016. Occup \& Health. 2018;34(03):403-406.

51. Regitz-Zagrosek V, Lehmkuhl E, Weickert MO. Gender differences in the metabolic syndrome and their role for cardiovascular disease. Clin Res Cardiol. 2006;95(3):147

52. Lee SJ, Arslanian SA. Cardiorespiratory fitness and abdominal adiposity in youth. Eur J Clin Nutr. 2007;61(61):561-5.

53. Park YS, Kwon HT, Hwang SS, et al. Impact of visceral adiposity measured by abdominal computed tomography on pulmonary function. J Korean Med Sci. 2011:26(6):771-7.

54. Regitzzagrosek V, Lehmkuhl E, Weickert MO. Gender differences in the metabolic syndrome and their role for cardiovascular disease. Clin Res Cardiol. 2006;95(3):136-47.

55. Xiangdong $W$, Ronghua $L$, Baojuan $M$, et al. Effects of visceral fat content on cardiopulmonary function and aerobic exercise ability of obese young women. Mod Prev Med. 2010;37(10):1907-9.
56. Wei YF, Wu HD. Candidates for bariatric surgery: morbidly obese patients with pulmonary dysfunction. J Obes. 2012;2012:878371.

57. Koenig SM, Koenig SM. Pulmonary complications of obesity. Am J Med Sci. 2001;321(4):249-79.

58. Santamaria F, Montella S, Greco L, et al. Obesity duration is associated to pulmonary function impairment in obese subjects. Obesity. 2011;19(8):1623-8.

\section{Publisher's Note}

Springer Nature remains neutral with regard to jurisdictional claims in published maps and institutional affiliations.
Ready to submit your research? Choose BMC and benefit from:

- fast, convenient online submission

- thorough peer review by experienced researchers in your field

- rapid publication on acceptance

- support for research data, including large and complex data types

- gold Open Access which fosters wider collaboration and increased citations

- maximum visibility for your research: over $100 \mathrm{M}$ website views per year

At BMC, research is always in progress.

Learn more biomedcentral.com/submissions 